Max-Planck-Institut für demografische Forschung

Max Planck Institute for Demographic Research

Konrad-Zuse-Strasse 1 - D-18057 Rostock · GERMANY

Tel +49 (0) 3812081 - 0; Fax +49 (0) 3812081 - 202;

http://www.demogr.mpg.de

MPIDR WORKING PAPER WP 2006-007

MARCH 2006

\title{
Anticipatory analysis and its alternatives in life-course research. Part 2: Marriage and first birth
}

Jan M. Hoem (hoem@ demogr.mpg.de)

Michaela Kreyenfeld (kreyenfeld@ demogr.mpg.de)

(C) Copyright is held by the authors.

Working papers of the Max Planck Institute for Demographic Research receive only limited review. Views or opinions expressed in working papers are attributable to the authors and do not necessarily reflect those of the Institute. 


\title{
Anticipatory analysis and its alternatives in life-course research. Part 2: Marriage and first birth
}

\author{
Reflections by Jan M. Hoem and Michaela Kreyenfeld
}

\begin{abstract}
In the second part of these reflections, we use the connection between marriage and first childbearing to demonstrate further issues involved in anticipatory analysis. We show that an anticipatory approach cannot be used to represent intentionality: People may marry with the intention of having a child, but the analyst should be weary of using anticipatory analysis to pick that up.
\end{abstract}

Keywords: anticipatory analysis, conditioning on the future, intentionality, marriage and first childbearing 


\section{Introduction}

The timing and the order of events are central elements in event-history analysis. A common understanding among event-history analysts is that $\mathrm{X}$ can only be a determinant of $\mathrm{Y}$ if $\mathrm{X}$ precedes $\mathrm{Y}$ in time. Any approach which reverses this order is anticipatory and violates a basic principle of statistical methodology. For that reason, strict methodologist will agree that anticipatory analysis is an unacceptable research strategy. Despite repeated warnings, anticipatory procedures are quite common in applied social-science research nevertheless. A major reason for this is that anticipatory analysis often provides straightforward summary indicators that more sophisticated modeling strategies are unable to furnish. In a first part of this paper, we illustrated this issue by means of the example of fertility indicators according to a woman's educational level (Hoem and Kreyenfeld 2006). In the present paper, we illustrate the issue once more through a study of the interrelationship between marriage and childbearing, again using an anticipatory approach that we have found in the literature. As an alternative, we also suggest a non-anticipatory strategy which is no novelty in event-history research. We have decided to make our reflections generally available nevertheless, particularly since conditioning on the future occurs so often in the social-science literature and since discussions of corresponding pitfalls in similarly simple cases seem to be rare. We hope that a clarification will prove as useful to others as it has been to us.

\section{Marriage in anticipation of parenthood}

Partnership formation, marriage, childbearing, and the purchase of a home are interrelated lifecourse events. People may form a partnership with the intention of marrying the partner. They often marry because they want children, or they buy a house in anticipation of family formation. The interrelation between two types of life-course events can be handled using one of them as a time-varying covariate in the analysis of the other, but there does not really exist any agreed-upon descriptive tool for handling intentionality. One suggestion that one can find in the literature is to fix an event on one of the processes and to study individual behavior on the other process in relation to the first (see, e.g., Wagner and Mulder 2001). Technically one subtracts the time of occurrence of an event on the second process from the fixed time of 
occurrence of the first and uses this difference as a waiting time for the second process, whether the difference is positive or negative. (The difference will of course be negative if the event on the fixed process occurs before the event on the other process.) In imitation of this approach we use such a procedure here to see whether one can say that marriages are often formed in anticipation of entry into parenthood. To this end, we fix the time of first birth to a woman and let marriage be a process which we study in relation to the first birth. We then calculate the duration of marriage at first birth by subtracting the respondent's age at marriage from her age at first birth. This duration will be negative if the child is born before marriage formation. ${ }^{1}$ We then compute and plot occurrence/exposure rates of marriage by duration and see that marriages are heaped around the arrival of the first child.

For an empirical illustration, we have used data from the German Family and Fertility Survey of 1992. We have selected women aged 30 to 39 years at the date of interview and have omitted respondents with invalid fertility or marriage histories. The computation just described cannot be done for childless respondents (one has to fix the time of entry into motherhood), so we have omitted them and got a remaining sample of 886 cases and 840 first marriages.

Figure 1 displays the marriage risks (occurrence/exposure rates), calculated as described above. The curve shows a clear pattern. Two years before first birth, marriage risks quickly increase, they peak during the year when the child is born and fall off rapidly thereafter. In summary, this looks like a strong coupling of the two events (marriage and first childbirth). According to this type of analysis, most marriages happen shortly before childbirth, most likely in anticipation of parenthood. In other words, many marriages are triggered by the motivation to have a child soon. If people make scripts of their lives, couples would think in terms of a plan for a good while ahead and would let plans for future childbearing guide present marriage formation behavior.

1 If one subtracts the age at marriage from the age at first birth, one gets negative values for respondents who married after they had their first child. Most computer programs will not estimate a survival or hazard function for negative durations. If one adds some arbitrary high number to the process time, one can perform the analysis. 
Figure 1: First marriage risks by 1000 women months, by age of first child

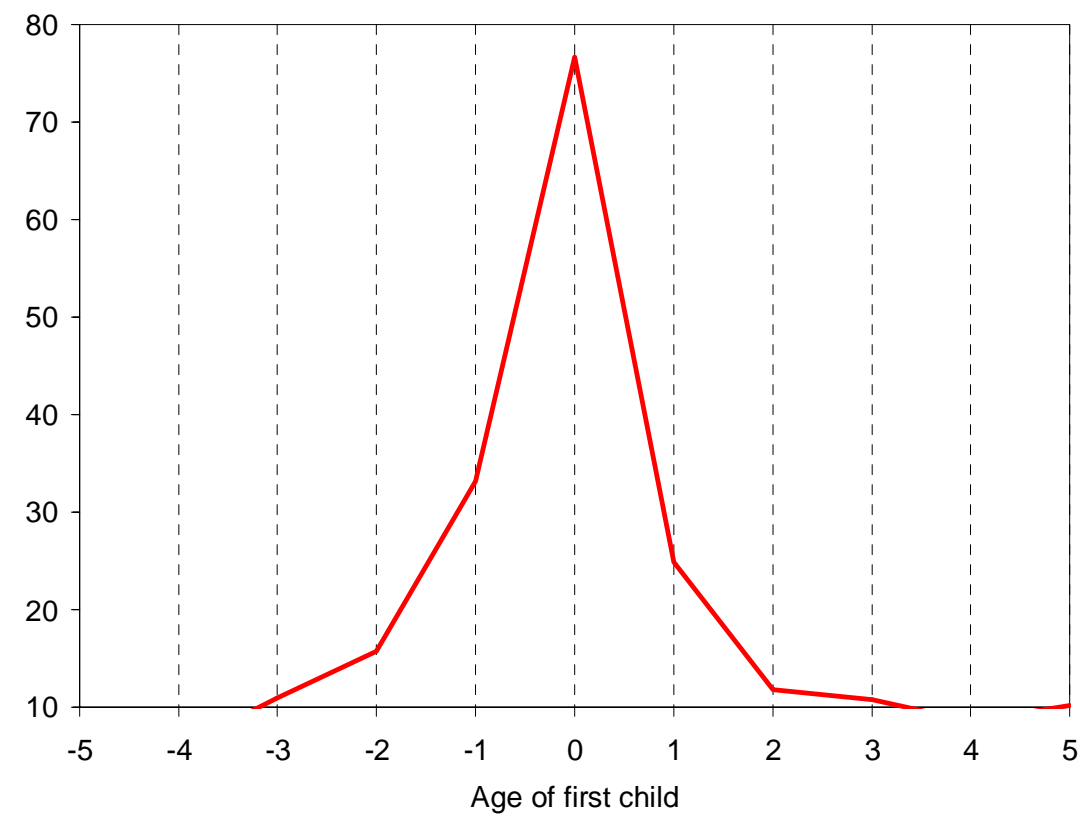

Notes: The sample comprises West German women with children aged 30 to 39 at the time of interview. The hazards are estimated for single years of age (see Table 1). The hazard rates are plotted against the start of each interval.

Source: German Family and Fertility Survey 1992 (our own estimates).

Table 1: First marriage risks by 1000 women months, by age of first child

\begin{tabular}{|c|c|}
\hline Age of child (in years) & Absolute marriage risks \\
\hline-5 & 4.34 \\
-4 & 5.86 \\
-3 & 10.95 \\
-2 & 15.73 \\
-1 & 33.18 \\
0 & 76.65 \\
1 & 24.89 \\
2 & 11.83 \\
3 & 10.79 \\
4 & 8.55 \\
5 & 10.20 \\
\hline
\end{tabular}

Notes: The sample comprises West German women with children aged 30 to 39 at the time of interview.

Source: German Family and Fertility Survey 1992 (our own estimates). 
The procedure that produced Figure 1 is problematic for several reasons. First, the presence of negative duration time in Figure 1 makes it obvious that the procedure is anticipatory. This is problematic in that a causal interpretation requires a logical order of cause and effect. From this perspective, childbirth cannot be a determinant of marriage if the child is born after marriage formation. Appealing to intentionality, one could perhaps argue as follows, however: Marriage is often motivated by a desire for children. To address how childbearing intentions impact on marriage one requires longitudinal data on fertility intentions. Such data are rarely available. Even though we are unable to observe a desire for children, we can observe later birth behavior. The latter must be highly correlated with past fertility intentions. It should therefore be possible to use childbearing behavior as a proxy for the effect of fertility intensions on marriage behavior. ${ }^{2}$ One of the pitfalls of this argumentation is that childbirth is not always the outcome of intended behavior. Also, the argument remains fairly vague about the duration between intention and action.

Second, it is problematic that the analysis only comprises respondents who experience a first birth. In fact the first birth must even have occurred before the end of the period of observation. However, childbearing had not come to an end for "our" respondents when the data were collected from our study population, so many respondents are eliminated needlessly.

Third, while a good analytical procedure would treat the two events (marriage and childbearing) in a reasonably symmetric manner, one need to take one of the two events as given in analyses of the kind just described. For this 'fixed' event, one cannot consider the censored cases (i.e., births after the time of data collection cannot enter the analysis, as we just mentioned). The sample is therefore selective. In our illustration we included women who were aged 30-39 at the time of interview. Most likely, many of the women who had children after the interview have a university degree. Since highly-educated women differ from others in their demographic behavior, the type of analysis that leads to diagrams like Figure 1 will be biased.

Fortunately, there is an alternative way to describe the coupling of marriage and first birth that avoids the pitfalls of anticipatory analysis and that also accounts for censoring, 
namely, to model the marriage and fertility transitions separately but in interaction. We now turn to this possibility.

\section{Separate modeling of the different transitions}

Methods for studying interrelations between two life-course processes have roots going back almost a century (DuPasquier 1912/13; see also Simonsen 1936). The ideas have also been become common in contemporary event-history research (see, e.g., Courgeau and Lelièvre 1992: 82ff.; Trond 1995; Blossfeld and Rowher 2002: 134ff.). The first step is to define a status space as in Figure 2. Boxes represent life-course states and arrows indicate possible transitions; the functions written beside the arrows represent transition intensities (hazards) that here depend on age $x$, duration $t$ of marriage, and duration $u$ since first birth, as the case may be.

Figure 2: State space of transitions around marriage formation and first birth

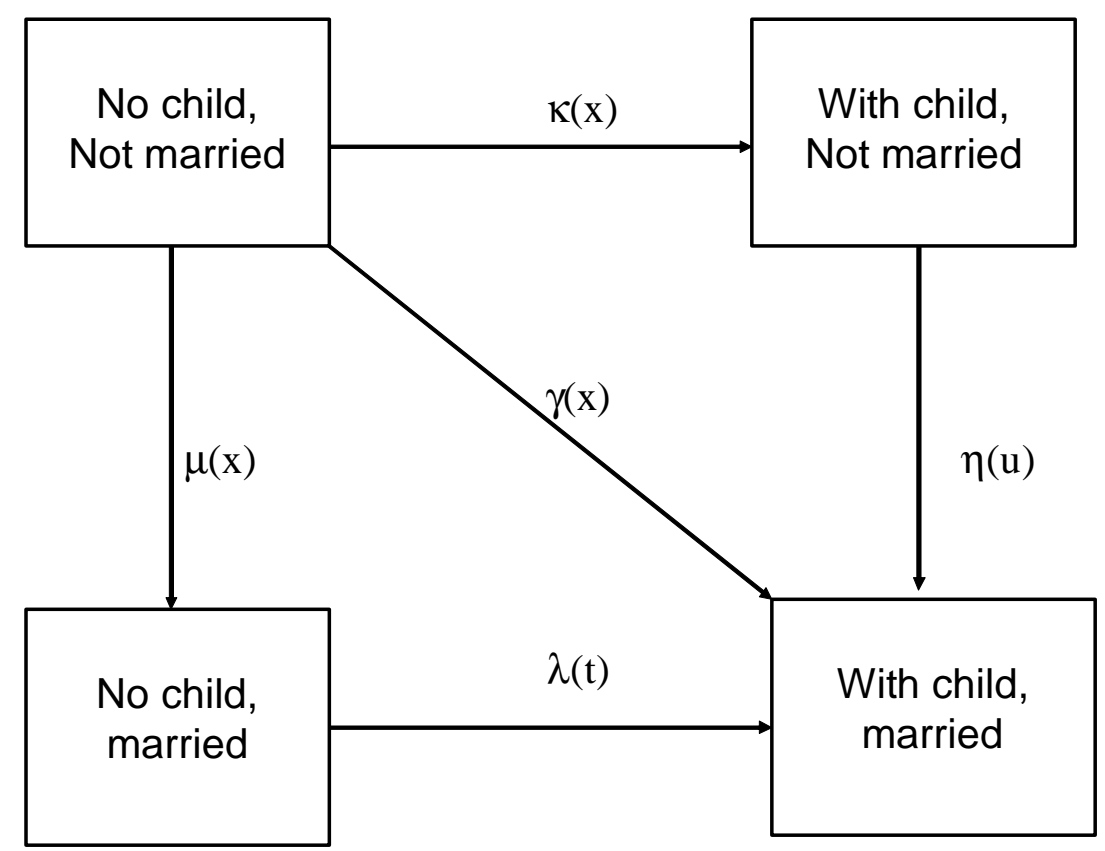


In this picture, $\kappa(x)$ denotes the first-birth intensity of a (childless) unmarried woman at age $x$. Her marriage-formation intensity is $\mu(x)$, and she has an intensity $\gamma(x)$ of the simultaneous occurrence of marriage formation and a first birth. The two latter hazards represent risks that compete with the risk of having a child while unmarried. Similarly, $\lambda(t)$ denotes the first-birth intensity for a woman who has been married for $t$ months, and $\eta(u)$ denotes the first-marriage intensity for a woman with a child born $u$ months ago. For simplicity of argument we disregard the woman's age in the two latter intensities, and we also disregard complications like marriage disruption and mortality.

Figure 3a through Figure 3d show the hazard rates. We have included the intensity $\gamma(x)$ of the simultaneous occurrence of marriage formation and a first birth because of its interest in principle, ${ }^{3}$ but it cannot be represented by a survival curve for our data set. There are only nine respondents (out of 1.003 who first married) who experienced birth and marriage in the same month, and this is too few to draw a sensible curve. In practice, we take $\gamma(x)$ to be identically zero in this application. 
Figure 3a: First-birth risks per 1000 woman-months, childless unmarried women

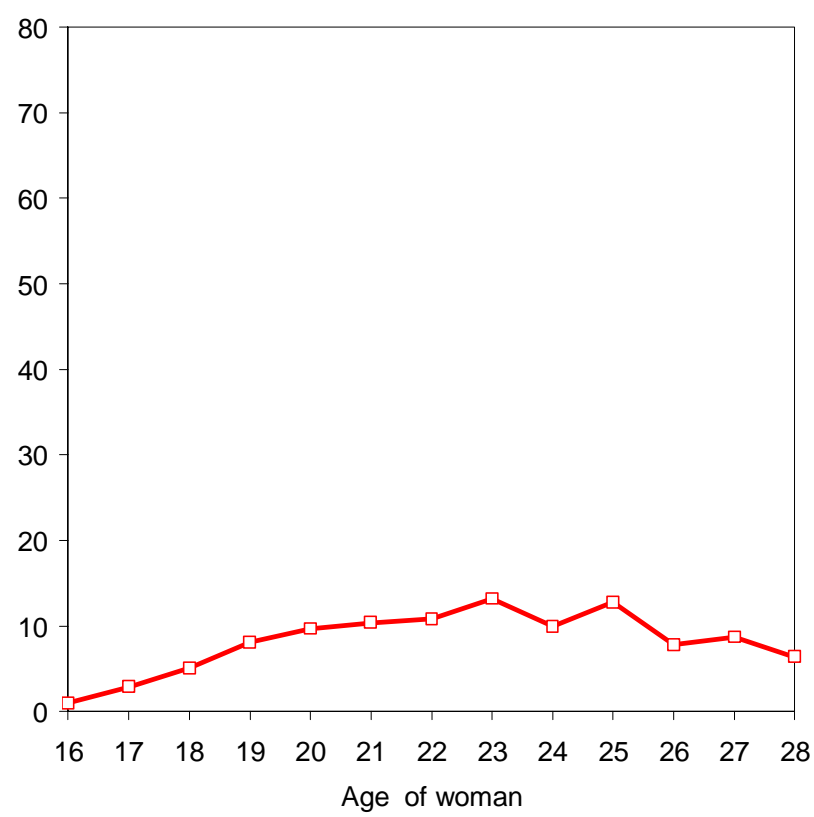

Figure 3b: First-marriage risks per 1000 woman-months, childless women, all ages combined

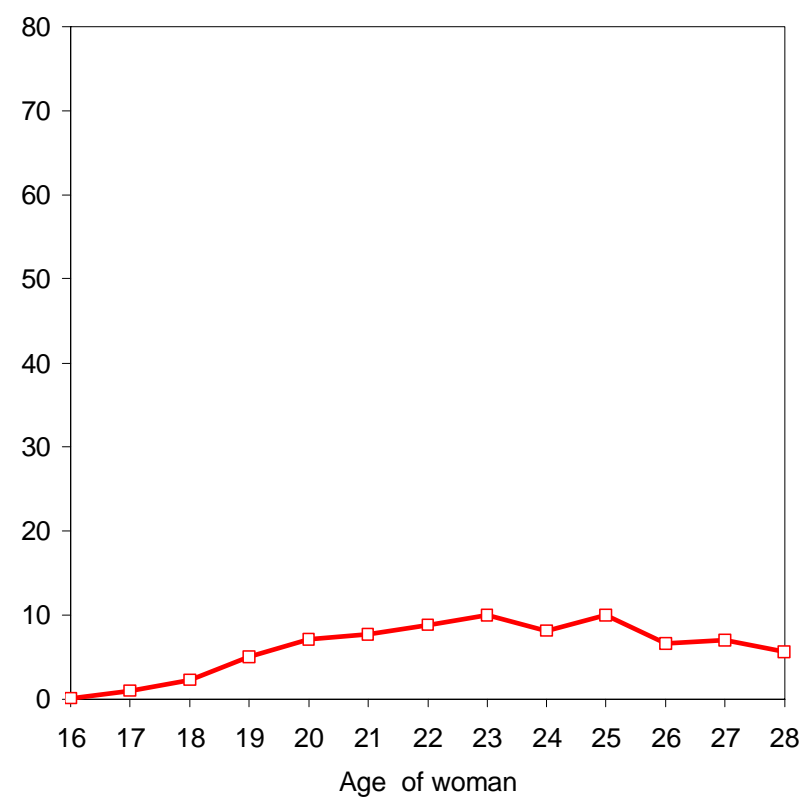


Figure 3c: First-birth risks per 1000 woman-months, childless married women, all ages combined

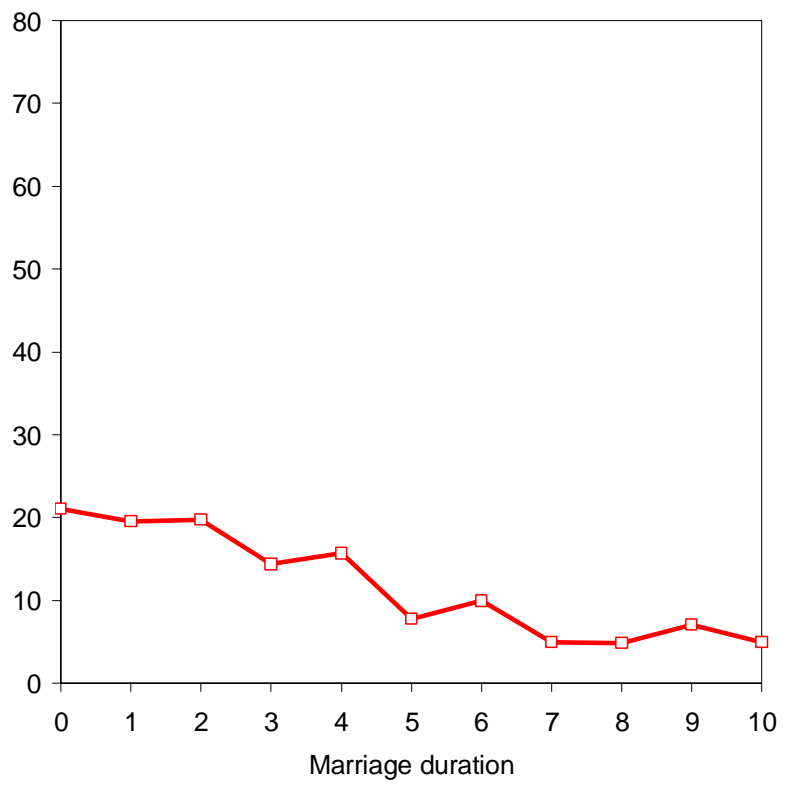

Figure 3d: First-marriage risks per 1000 woman-months, women with children, all ages

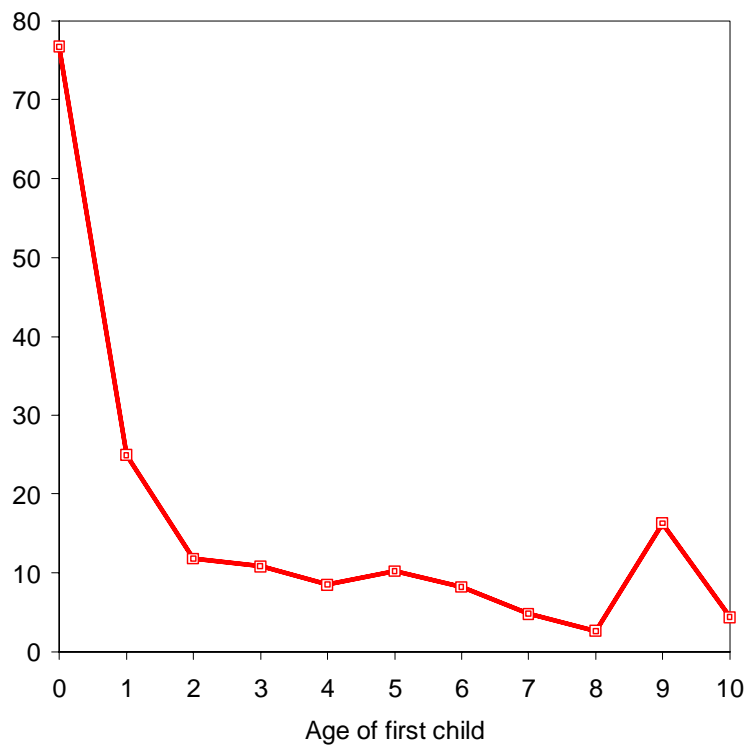

Note: The sample comprises West German women aged 30 to 39 at the time of interview. The hazards are estimated for single years of age (see Table 2). The hazard rates are plotted against the start of each age interval.

Source: German Family and Fertility Survey 1992 (our own estimates) 
Table 2: First-birth and marriage risk per 1000 woman-months

\begin{tabular}{|ccc|ccc|}
\hline $\begin{array}{c}\text { Age of } \\
\text { woman }\end{array}$ & Marriage risk & Birth risk & $\begin{array}{c}\text { Age of first } \\
\text { child }(u) \text { or } \\
\text { duration of } \\
\text { marriage }(t) \\
\text { in years }\end{array}$ & $\begin{array}{c}\text { Marriage } \\
\text { risk }\end{array}$ & Birth risk \\
\hline 16 & 1.00 & $\kappa(x)$ & & $\eta(u)$ & $\lambda(t)$ \\
17 & 2.90 & 1.00 & 1 & 76.70 & 21.10 \\
18 & 5.10 & 2.30 & 2 & 11.80 & 19.60 \\
19 & 8.10 & 5.00 & 3 & 10.80 & 14.40 \\
20 & 9.70 & 7.10 & 4 & 8.50 & 15.70 \\
21 & 10.40 & 7.70 & 5 & 10.20 & 7.80 \\
23 & 10.80 & 8.80 & 6 & 8.20 & 10.00 \\
24 & 13.20 & 10.00 & 7 & 4.80 & 5.00 \\
25 & 10.00 & 8.10 & 8 & 2.60 & 4.90 \\
26 & 12.80 & 10.00 & 9 & 16.30 & 7.10 \\
27 & 7.80 & 6.60 & 10 & 4.40 & 5.00 \\
\hline
\end{tabular}

Notes: The sample comprises West German mothers aged 30 to 39 at the time of interview. Source: German Family and Fertility Survey 1992 (our own estimates).

\section{Mirrored hazard rates ${ }^{4}$}

The procedure that builds on the transition space in Figure 2 and on the intensities in Figures 3a-d and Table 2 safely represents the dynamics of the interactions between marriage and first birth, but it does not lead immediately to anything like the neat curve in Figure 1, which seemed so nicely to demonstrate the strong coupling of marriage and childbirth. Obviously, this is so because the transitions are treated separately. The following procedure moves toward a similar picture by combining two of the separate transitions.

Let us plot the two functions $\lambda(t)$ and $\eta(u)$ from Figures $3 \mathrm{c}$ and $3 \mathrm{~d}$ back-to-back in a diagram with the origin ('zero-point') in the middle of the abscissa, the duration $t$ of marriage running leftwards from that origin, and the age $u$ of the first child running rightwards, as in Figure 4. If there is a much increased intensity of childbirth just after marriage, and similarly a much increased intensity of marriage shortly after first birth, one would expect the resulting diagram to show a cusp much as in Figure 1. As we see, this turns out not to be the case, in 
that a marriage does not "produce" childbearing to anything like the extent that childbearing "produces" a marriage. The right-hand curve in Figure 4 is the same as the right-hand branch of the curve in Figure 1, but the left-hand curve in Figure 4 is nothing like the left-hand branch in Figure 1. This goes to show that the anticipatory procedure is badly biased. One cannot represent the fact that many marriages are formed with the intention of producing a birth in the manner of Figure 1. In event-history analysis intentionality is represented indirectly, namely via the form of the hazard curves of the individual life transitions. Intentionality is something else than an anticipatory procedure.

Figure 4: Back-to-back hazard rates (hazard are represented in 1000 woman-months)

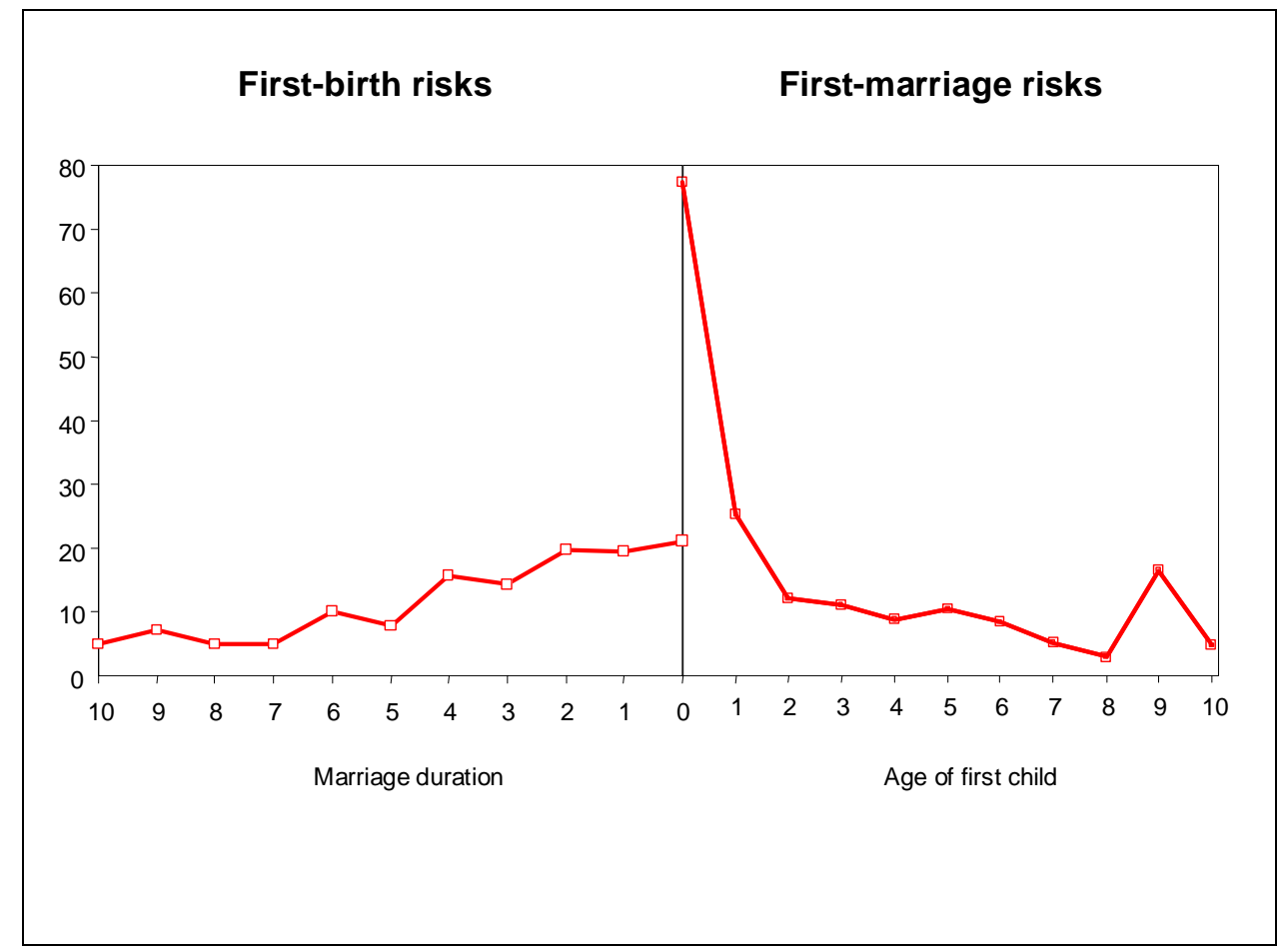

Note: The sample comprises West German women aged 30 to 39 at the time of interview. The hazards are estimated for single years of age. The hazard rates are plotted against the start of each age interval.

Source: German Family and Fertility Survey 1992 (our own estimates) 


\section{Conclusions}

The goal of both parts of this two-part paper has been to demonstrate some shortcomings of anticipatory analysis in life course research and to indicate that there are safer nonanticipatory research strategies, although they also sometimes have their problems. In Part 1 we addressed the interrelation between education and fertility and found it cumbersome to provide summary fertility indicators for women at different educational levels without conditioning on the future. In the present Part 2 we have focused on the empirical analysis of two parallel event-history processes. We have shown that a much-used anticipatory procedure makes marriage intensities appear to increase in anticipation of parenthood, while a nonanticipatory approach provides a completely different picture.

We make no pretense that this paper provides anything really novel in the methodological literature. We feel, however, that our contribution has clarified some matters that need not remain problematic, the way they appear in the current empirical literature. We hope that our two case studies can serve as a reminder that the risk of bias inherent in most anticipatory analysis can be avoided if one uses procedures not much more difficult than a simple extension of age-old life-table methods.

\section{Acknowledgement}

The authors wish to thank the Bundesinstitut für Bevölkerungswissenschaft (BiB) for its permission to use the FFS data on which parts of this study are based.

\section{References}

Billari, Fransesco C. (2001): The analysis of early life courses: Complex descriptions of the transition to adulthood. Journal of Population Research 18: 119-142.

Blossfeld, Hans-Peter/ Rohwer, Götz (2002): Techniques of Event History Modeling: New Approaches to causal analysis. $2^{\text {nd }}$ edition. Mahwah (New Jersey): Lawrence Erlbaum.

Courgeau, Daniel/ Lelievre, Eva (1992): Event History Analysis in Demography. Oxford: Clarendon Press.

DuPasquier, Louis G. (1912/13): Mathematische Theorie der Invaliditätsversicherung. Mitteil. Vereinigung schweizerischer Versicherungsmathematiker, Vol 7, 1-7, and Vol 8, $1-153$.

Hoem, Jan M./ Kreyenfeld, Michaela (2006): Anticipatory analysis and its alternatives in lifecourse research. Part 1: education and fertility (under preparation). 
Mulder, Clara/ Wagner, Michael (2001): The connections between family formation and firsttime home ownership in the context of West Germany and the Netherlands: European Journal of Population 17: 137-164.

Petersen, Trond (1995): Models for interdependent event-history data: specification and estimation. Sociological Methodology 25, 317-375.

Simonsen, William (1936): Über die Grundformeln der Invaliditätsversicherung. Skandinavisk Aktuarietidskrift 19, 27-41. 